\title{
УД-I-7 \\ ПРИМЕНЕНИЕ МЕТОДА АЭС-ИСП С ГРАДУИРОВКОЙ ПО ОТНОШЕНИЯМ КОНЦЕНТРАЦИЙ ДЛЯ АНАЛИЗА ГЕОЛОГИЧЕСКИХ И ТЕХНИЧЕСКИХ МАТЕРИАЛОВ, РУД И КОНЦЕНТРАТОВ \\ Каримова Т.А. ${ }^{1}$, Бухбиндер Г.Л. ${ }^{2}$, Качин С.В. ${ }^{1}$ \\ ${ }^{1}$ Сибирский федеральный университет, Красноярск, Россия \\ ${ }^{2}$ Представительство Intertech Trading Corporation в Красноярске, Красноярск, Россия malaeva.tatyana@bk.ru
}

DOI: 10.26902/ASFE-11_25

Градуировка по отношениям концентраций обладает значительным потенциалом повышения точности результатов анализа геологических материалов с использованием атомно-эмиссионной спектрометрии с индуктивно-связанной плазмой (АЭС-ИСП).

Для подготовки образцов к анализу предложены 2 схемы: разложение в смеси кислот $\mathrm{HCl}, \mathrm{HNO}_{3}, \mathrm{HF}$ (и $\mathrm{H}_{3} \mathrm{BO}_{3}$ ) и сплавление с $\mathrm{LiOH}$. Растворение в смеси кислот осуществляли в системе подготовки проб HotBlock 200, оснащенной тефлоновыми пробирками-автоклавами вместимостью $55 \mathrm{~cm}^{3}$. Сплавление образцов с LiOH выполняли в серебряных тиглях при температуре $670-820^{\circ} \mathrm{C}$. Такой прием обеспечивает полный перевод в раствор соляной кислоты геологических материалов, руд, концентратов, огнеупоров и других технических материалов. Для градуировки спектрометра iCAP 7400 Duо использовали ГСО состава горных пород и руд, оксиды кальция и кремния, карбонильное железо.

Для анализа образцов железорудного сырья при расчете содержаний компонентов предложены формулы 1 - для учета кислорода, необходимого для окисления закиси железа в оксид железа, и 2, так как железо представлено в виде суммы $\mathrm{FeO}$ и $\mathrm{Fe}_{2} \mathrm{O}_{3}$ :

$$
\begin{aligned}
& \frac{\mathrm{C}_{\mathrm{Al} 2 \mathrm{O} 3}}{\mathrm{C}_{\mathrm{Fe} 2 \mathrm{O} \text { изм }}}+\frac{\mathrm{C}_{\mathrm{CaO}}}{\mathrm{C}_{\mathrm{Fe} 2 \mathrm{O} \text { изм }}}+\ldots+\frac{\mathrm{C}_{\mathrm{ZrO} 2}}{\mathrm{C}_{\mathrm{Fe} 2 \mathrm{O} \text { изм }}}=\frac{100 \%-\text { П.П.П. }+0,111^{*} \mathrm{C}_{\mathrm{FeO}}}{\mathrm{C}_{\mathrm{Fe} 2 \mathrm{O} \text { изм }}}-1 \\
& \mathrm{C}_{\mathrm{Fe} 203 п р}=\left(\mathrm{C}_{\mathrm{Fe} 2 \mathrm{O} 3 \text { изм }} * 0,6994-\mathrm{C}_{\mathrm{FeO}} * 0,7773\right) * 1,4299
\end{aligned}
$$

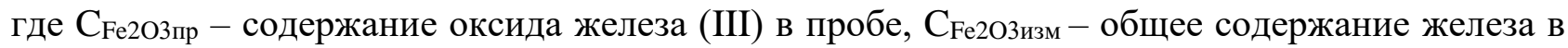
виде оксида железа (III), измеренное на спектрометре, $\mathrm{C}_{\mathrm{FeO}}$ - содержание оксида железа (II), определенное титриметрически.

При анализе геологических материалов с содержанием $\mathrm{SiO}_{2}$ более $20 \%$ предложена формула для расчета содержаний компонентов:

$\frac{\mathrm{C}_{\mathrm{Al} 2 \mathrm{O} 3}}{\mathrm{C}_{\mathrm{SiO} 2}}+\frac{\mathrm{C}_{\mathrm{CaO}}}{\mathrm{C}_{\mathrm{SiO} 2}}+\ldots+\frac{\mathrm{C}_{\mathrm{ZrO} 2}}{\mathrm{C}_{\mathrm{SiO} 2}}=\frac{100 \% \text { - п.п.п. }}{\mathrm{C}_{\mathrm{SiO} 2}}-1$

Для анализа образцов, содержащих менее $20 \% \mathrm{SiO}_{2}$ и более $20 \% \mathrm{CaO}$ в качестве основного компонента рассмотрена возможность использования оксида кальция. В этом случае для расчета содержаний элементов предложена формула:

$\frac{\mathrm{C}_{\mathrm{Al} 2 \mathrm{O} 3}}{\mathrm{C}_{\mathrm{CaO}}}+\frac{\mathrm{C}_{\mathrm{Fe} 2 \mathrm{O} 3}}{\mathrm{C}_{\mathrm{CaO}}}+\ldots+\frac{\mathrm{C}_{\mathrm{ZrO} 2}}{\mathrm{C}_{\mathrm{CaO}}}=\frac{100 \%-\text { П.П.П. }}{\mathrm{C}_{\mathrm{CaO}}}-1$

Выполнено сравнение повторяемости и промежуточной прецизионности при использовании градуировки по отношениям концентраций, в абсолютных интенсивностях и с использованием внутреннего стандарта. Градуировка в относительных концентрациях обеспечивает лучшие метрологические характеристики по сравнению с другими вариантами градуировки геологических материалов. Основными факторами такого улучшения являются: исключение погрешности калибровки мерной посуды и погрешности взвешивания навесок анализируемых материалов из суммарной погрешности анализа; измерение больших значений интенсивностей элемента основы; более высокая точность измерения отношения интенсивностей по сравнению с измерением абсолютных интенсивностей. 